\title{
LAS PUBLICACIONES Y LA INVESTIGACIÓN SOBRE MUJERES ARTISTAS EN ESPAÑA ${ }^{1}$
}

\author{
Pilar Muñoz López ${ }^{2}$
}

\begin{abstract}
Las publicaciones y la investigación sobre mujeres artistas en España
Resumen: El tema de las mujeres artistas ha sido escasamente tratado en la abundante bibliografía de Historia del Arte. La mayor parte de las publicaciones que se han editado en los últimos años son fundamentalmente de carácter divulgatorio de la actividad de las artistas en el contexto internacional y en nuestro país. En el artículo se revisan los libros y artículos publicados y, finalmente, se exponen los contenidos de mi obra Artistas españolas en la dictadura de Franco. 1939-1975, que, desde una perspectiva histórica, trata de dar a conocer la actividad creativa de muchas artistas españolas en este periodo histórico.

Palabras clave: Publicaciones, investigación, mujeres artistas en España.
\end{abstract}

Publications and Research about Women Artists in Spain

Abstract: The topic of Women Artists has been hardly presented in abundant bibliography of Art History. The majority of publications issued in latest years are popular science books about the activity of artists in an international context and in our country. In this paper I revise books and articles, and finally, I thoroughly explain thoroughly the contents of my book Artistas españolas en la dictadura de Franco. 1939-1975, which from an historic perspective, attempts to show the prominence of creative activity from many Spanish women artists in this historic period.

Key words: Publications, research, women artists in Spain.

El tema de las mujeres artistas en el arte ha sido escasamente tratado en la abundante bibliografía de Historia del Arte. La mayor parte de las publicaciones relacionadas con esta cuestión que se han editado en los últimos años son fundamentalmente de carácter divulgatorio de la actividad de las artistas en el contexto internacional y en nuestro país. En el contexto internacional comenzaron a surgir obras que planteaban el tema a partir de los años 70, especialmente en Estados Unidos e Inglaterra. Esto fue una consecuencia del movimiento feminista que en esta década surgió en Estados Unidos, a partir del cual se dieron a conocer muchas artistas del pasado y las que trabajaban a partir de las ideas feministas.

\footnotetext{
${ }^{1}$ Fecha de recepción: 13/12/2014.

Fecha de aceptación: 20/12/2015.

${ }^{2}$ Profesora Contratada Doctora, Departamento de Educación artística, plástica y visual, Universidad Autónoma de Madrid; $\bowtie$ pilarmunozlopez@gmail.com.
} 
Generalmente, en las publicaciones especializadas se ha ignorado o minusvalorado cualquier trabajo de creación realizado por mujeres, o se ha relegado al ámbito de la artesanía (es decir, no arte) o de otros géneros considerados menores; o simplemente, se ha ocultado o atribuido a artistas varones, pues la ideología hegemónica consideraba que la instrucción de las mujeres debía orientarse exclusivamente a los aspectos prácticos de la vida doméstica y a las funciones de esposa y madre, y que cualquier actividad de creación en la mujer, constituía un signo de inadecuación biológica o psicológica para sus funciones tradicionales. Por otra parte, la producción artística de las mujeres se vinculaba desde el siglo XVIII con la educación "de adorno" de las damas de las clases sociales privilegiadas, y se toleraba como una manera adecuada de llenar unos tiempos excesivos de ocio (De Diego 1987).

Sin embargo, desde finales del siglo XIX y comienzos del XX comienzan a aparecer publicaciones sobre artistas españolas, debido a la gran popularidad que la práctica de la pintura había alcanzado entre las señoras y señoritas de las clases hegemónicas. Durante el siglo XIX y las primeras décadas del XX la práctica de la pintura constituía un entretenimiento adecuado a las mujeres de las clases superiores, asegurándoles valores morales que podían transmitir a los hijos, como exponen diferentes textos. En este punto, encontramos una cuestión característica de las escasas bibliografías que se han ocupado de mujeres artistas, y que consiste en la valoración de su biografía y de su obra en función de la valoración social y moral de su actividad y su conducta.

Es significativa la idea presente en la sociedad y en la mayoría de los casos, corroborada por las propias escritoras e incluso artistas, de la incapacidad de la mujer para la creación que incluso podemos constatar en muchos escritos de hombres y mujeres hasta bien entrado el siglo XX. Podemos considerar pioneras en el interés por las artistas españolas a algunas publicaciones de finales del XIX y principios del XX:

En 1903, se publica la obra de José Parada y Santín Las pintoras españolas. El autor dice, como expresión del sentir general de la época: "Es condición de la mujer que, aunque en alguna ocasión con su talento se levanta hasta el nivel de la inteligencia masculina, le está vedado alcanzar la sublime a que han llegado los grandes genios con 
su potencia creadora, acaso por la insuficiencia de sus estudios" (Parada y Santín 1903: 80). Sin embargo, la práctica de la pintura es beneficiosa para las damas: “[...] pues su cultivo, que además constituye una distracción útil y hasta higiénica, podría contribuir a llenar los huecos que deja la deficiente educación que se da a la mujer española, ocios que hoy ocupa el coquetismo y la frivolidad" (1903: 80). Sin embargo, según este autor, "[...] una mujer estudiando leyes y tratando de ejercer ciertas profesiones, nos parece un absurdo moral, [...] porque esta actividad sin objeto se convierte en un elemento pernicioso para el cerebro y la organización que la abriga" (77-78).

No obstante estas ideas presentes en la ideología de la época, el hecho de que la obra trate exclusivamente de "pintoras españolas" indica posiblemente que existía un gran número de mujeres que llevaban a cabo actividades artísticas en la época, y a quienes interesaba el tema tratado por el autor. Las fuentes posiblemente estén en la obra de Ceán Bermúdez Diccionario de los más ilustres profesores de las Bellas Artes en España, publicado en 1800, aunque incluye a algunas monjas pintoras que realizaban obras religiosas para los conventos en los que vivían con escasa proyección al exterior. Se trata, pues de una relación de artistas desde el siglo XVIII.

También encontramos algunas obras de escritoras en las primeras décadas del siglo XX. Entre 1900 y 1918 el feminismo hizo su aparición en Europa reivindicando los derechos civiles, sociales y políticos y la emancipación de las mujeres. En España este movimiento tuvo eco especialmente en Cataluña, a través de publicaciones y revistas como Feminal (1907-1917), fundada por Carme Karr y Dolores Monserdà, y que desde planteamientos conservadores y cristianos, reivindicaba mejoras en la calidad de la educación de las mujeres, la elevación de su nivel intelectual y un espacio para la mujer en los círculos culturales y sociales, lo cual representaba una trasgresión de los códigos sociales de género vigentes en la época.

La influencia de las ideas feministas tuvo repercusión en las obras y los comportamientos sociales y profesionales de las mujeres que polemizaron con sus escritos o su actividad artística en estos años en España. Al igual que en la pintura, en la literatura decimonónica surgen en nuestro país algunas escritoras que adquieren prestigio 
y fama, como en los casos de Emilia Pardo Bazán, Fernán Caballero, seudónimo masculino que esconde a Cecilia Bölh de Faber, o Rosalía de Castro.

Emilia Pardo Bazán (1851-1921) trata el tema de las actividades artísticas de las damas en un artículo en el que reivindica mejoras educativas para las mujeres:

[...] la filosofía y las lenguas clásicas serían una prevaricación; en cambio, transigen y hasta gustan de los idiomas, la geografía, la música y el dibujo, siempre que no rebasen del límite de aficiones y no se conviertan en vocación seria y real. Pintar platos, decorar tacitas, emborronar un "efecto de luna", bueno; frecuentar los museos, estudiar la naturaleza, copiar del modelo vivo, malo, malo. (Pardo Bazán 1890 [1976]: 124-125).

Surgen también periodistas vinculadas generalmente a las revistas femeninas. Y algunas de ellas, como Concepción Gimeno de Flaquer (1852-1919), activa feminista, editora, periodista y novelista, que alcanzó gran prestigio en su época, trataron en sus escritos de favorecer el reconocimiento de las mujeres artistas. En 1877 escribió en su obra La mujer española. Estudios acerca de su educación y sus facultades intelectuales:

Cuando la mujer reciba en toda su amplitud la ilustración a que es acreedora, cuando se ocupen de facilitarle los conocimientos artísticos de que carece, podrá descollar en las nobles artes. La mujer posee en su alma el sagrado fuego de la inspiración, en su frente la divina chispa que todo lo anima, y en su inteligencia el numen creador e inagotable. [...] La mujer nace artista como nace artista el ruiseñor. Si no se han distinguido todas las mujeres dedicadas al arte de Murillo, es porque no se ha tratado de hacerles adquirir conocimientos, sino de enseñarles habilidades con objeto de hacer vano y ostentoso alarde. La educación pictórica de la mujer ha estado hasta hoy notablemente desatendida: limitada a empíricas instrucciones, difícilmente ha conseguido salir de copista, y muchas han visto morir sus ilusiones sin poder realizar el ideal de los sacerdotes del arte, o sea la composición. (Gimeno de Flaquer 1877: 37-66-67)

En relación a la infanta Paz de Borbón escribe en 1915: 
Antiguamente creían algunas mujeres que el título de artista o escritora las autorizaba para romper con las tradiciones anexas al sexo femenino y con las preocupaciones que cada época impone. Con tales prejuicios el título de escritora o artista asustaba a la gente medrosa; en opinión de ésta ser artista o literata era poseer una patente que permitía cometer las mayores rarezas, extravagancias y ridículas excentricidades. Entonces la escritora o artista no tenía lugar definido en la sociedad, mientras que ahora es reconocida como miembro de una clase inteligente que marcha a la vanguardia del progreso. La "bas blue" ha desaparecido; la artista o literata de nuestros días quiere ser ante todo mujer, y a este fin hace frecuentemente el doloroso sacrificio de nivelarse con inteligencias inferiores para no levantar a su paso tempestades de odio. La literata o artista de alta clase en nuestros días, es completamente femenina en su vida privada; habla como todas las damas cultas, recibe de igual modo, educa a sus hijos y se viste con arreglo al último figurín. La literata de la época moderna conoce que es más sensato doblegarse a la opinión, que desafiarla, y por eso se somete a ella. (Gimeno de Flaquer 1915: 200-201)

Se refleja muy bien en este texto la inquietud de las "artistas y literatas" por no llamar la atención en relación a un posible comportamiento escandaloso o extravagante asociado a su actividad artística. Nos está hablando, pues, de mujeres de clase alta (quizá su propio caso), que no pretenden transgredir las normas sociales asociadas a su condición. Las mujeres de clase social elevada que podían practicar estas actividades debían, al mismo tiempo, desarrollar estrategias para no levantar sospechas en su medio social, con un comportamiento adecuado a su rango y "plegarse a inteligencias inferiores para no despertar tempestades de odio". Se trata de justificar las actividades artísticas y literarias para no levantar sospechas en un mundo que negaba a las mujeres la posibilidad de ejercer actividades reconocidas y mostrarlas en la esfera pública.

La preocupación de muchas mujeres por acceder, a través de los estudios artísticos, a un desarrollo personal mayor, así como a la posibilidad de conseguir medios de vida a través de su trabajo, especialmente identificable en la clase media, se expresa en algunos textos, como el de la escritora Carmela Eulate Sanjurjo (1871-1961), quien, aún defendiendo el modelo tradicional de mujer, dice en 1917:

Existe una enorme producción moderna en las Exposiciones anuales, cuyo movimiento vertiginoso no es posible seguir, y cuyos nombres acumulados en los 
catálogos junto a los de los hombres, dicen mucho y no dicen nada. Dicen mucho en cuanto afirman la posibilidad de la mujer de hallar en el arte lo que puede llamarse un "metier" y vivir de sus pinceles, y vender cuadros y retratos que adornen las galerías modernas: no dicen nada en cuanto recapacitemos que ninguno de esos nombres está orlado con el nimbo del Genio, y sus pequeñas victorias personales equivalen a una gran derrota colectiva, frente a la magnitud de las obras del "Hombre". (Eulate Sanjurjo 1917: 317)

La cita de Carmela Eulate nos ofrece una visión bastante precisa de la situación de las mujeres creadoras en las artes plásticas en aquellos años. No olvidemos que los espectadores de las obras, valoraban no sólo la calidad de la misma, sino si se correspondían con las expectativas sociales en relación a las obras de "señoras" y "señoritas" en las que se juzgan también sus cualidades morales, y otros valores asociados a los estereotipos dominantes sobre la vida de las mujeres, como el aspecto físico o su adscripción de clase. También se adhiere a las ideas dominantes sobre la incapacidad creativa de las mujeres así como a la superioridad "natural" del hombre, mostrando la interiorización social general de la inferioridad de las mujeres en la creación artística; un complejo de inferioridad que se manifiesta claramente incluso en este grupo de mujeres, periodistas o escritoras, que habían roto con los condicionamientos de la época escribiendo en publicaciones periódicas o literarias que en ocasiones lograron un gran éxito. Sin embargo, Carmela Eulate Sanjurjo constituye un ejemplo de mujer creadora con su destacada actividad como traductora de escritores árabes, hindúes, franceses e ingleses, escritora de novelas y ensayos y feminista en obras como La muñeca (1895), La familia Robredo (1907) o El asombroso doctor Jover (1930) entre otras, en las que el tema de la mujer es el asunto fundamental. En La mujer en el arte: inspiradoras (1915) presenta una galería de mujeres que inspiraron y colaboraron con los hombres más destacados en el Renacimiento y en La mujer en el arte: creadoras (1915) aboga por la necesidad de la educación de la mujer para que ésta pueda desarrollarse plenamente en todos los terrenos, incluido el artístico.

En 1927 Carmen de Burgos, “Colombine” (1878-1932), publicó La mujer moderna y sus derechos, uno de los más importantes ensayos feministas de la época. Carmen de Burgos Segui fue una de las más destacadas defensoras de la mujer desde comienzos del 
siglo hasta los años 30. A lo largo de estos años escribió numerosos artículos de prensa, ensayos y novelas, además de un gran número de conferencias, en los que manifestó su preocupación por la situación de la mujer contribuyendo a la difusión del feminismo. Los temas que le preocupan fundamentalmente son la educación, el divorcio, el voto, el trabajo femenino o la prostitución.

Además de su numerosa producción literaria y ensayística, su pensamiento feminista queda también reflejado en sus escritos artísticos, en los que podemos calificarla como precursora de la crítica feminista de arte. Entre los temas que desarrolla en esta faceta de su obra, destaca su preocupación por la mujer como creadora y como musa, la iconografía femenina presente en las obras de arte de todos los tiempos, y su deseo de reivindicar las prácticas femeninas en la costura y la artesanía como "Arte”, rechazando el menosprecio de la visión masculina de estas actividades. Adopta una precursora postura ante las actividades manuales y artesanales realizadas tradicionalmente por la mujer, como las labores de aguja, el bordado y el encaje, a las que equipara a las artes mayores, especialmente a la pintura, contribuyendo así a subvertir las tradicionales jerarquías artísticas, que, como analizan Parker y Pollock (1981: 51), se relacionan con la categorización de hombres y mujeres en la sociedad.

A pesar de ser autodidacta, sentía un vivo interés por el arte llegando a ser nombrada en 1911 profesora de la Escuela de Artes y Oficios de Madrid en la asignatura de Historia del Arte (Núñez Rey 2005: 283). Sus artículos de crítica artística e historia del arte aparecieron en prensa o revistas no especializadas, como Heraldo de Madrid, ABC, La Correspondencia de España, Prometeo, etc. Expuso sus ideas sobre la mujer como creadora artística en muchas de las conferencias que impartió, además de en sus obras. En La mujer moderna y sus derechos dice:

\begin{abstract}
Se argumenta que no hemos producido obras de arte y de ciencia tan admirables como las de los hombres, es cierto. Pero oíd lo que a propósito de esto dice Taine: "Todos los descubrimientos de verdades, todos los inventos de utilidad han sido conquistados por los hombres libres, los esclavos no inventaron nada" y añade: "Los ciudadanos libres deben su superioridad a las ventajas de su situación no a la superioridad de la raza". Esto puede aplicarse a la mujer que no pudo desarrollar
\end{abstract}

Raudem - Revista de Estudios de las Mujeres - Vol. 3, 2015 ISSN: 2340-9630 
sus facultades en la esclavitud a la que se le sometía. Y, sin embargo, aún así, hemos tenido una gloria indisputable. La de inspiradoras. ¿A qué sentimiento se deben las estrofas de Dante, las armonías de Beethoven, las imágenes de Rafael y las estatuas de Miguel Ángel? (Burgos 1927: 256)

Aunque apenas hace referencia en sus escritos a la mujer como creadora y artista, uno de los temas recurrentes de Carmen de Burgos fue el de la mujer como musa e inspiradora de las obras de arte masculinas.

En un artículo de María Zambrano aparecido en 1947 en la revista Sur, y que reflejaba los contenidos expuestos en sus conferencias sobre la historia de la mujer, que impartió en La Habana y Puerto Rico en 1940, 1942 y 1943, y en el que comentaba el libro de su amigo Gustavo Pittaluga (1946), dice al final:

[...] Y es que hay un problema pavoroso que el autor ha soslayado: ¿puede la mujer ser individuo" en la medida en que lo es el hombre? ¿Puede tener una vocación además de la vocación genérica sin contradecirla? ¿Puede una mujer, en suma, realizar la suprema y sagrada vocación de la Mujer siendo además una mujer atraída por una vocación determinada? ¿Puede unir en su ser la vocación de la Mujer con una de esas vocaciones que han absorbido y hecho la grandeza de algunos hombres: Filosofía, Poesía, Ciencia, es decir, puede crear la mujer sin dejar de serlo? El precio de la creación del hombre ha sido muy alto y sus condiciones muy rigurosas: soledad, angustia, sacrificio. La mujer ha ofrecido su sacrificio permanente sin traspasar el lindero de la "creación". ¿Le será permitido hacerlo, podrá arriesgarse en un nuevo sacrificio sin arriesgar la continuidad de la especie, sin dejar de ser la gran educadora y guía del hombre? (Zambrano 1947:69)

Vemos como a través de esta reflexión se sitúa cercana a la ideología de su época, que arrastra tras sí la ancestral ideología sobre el ser de "la mujer", situando éste en su tradicional papel de madre y continuadora de la especie, o en los aspectos educativos del hombre. Sus dudas sobre la posibilidad de que las mujeres puedan llevar a cabo una vocación o una profesión laboral sin poner en peligro "la continuidad de la especie", olvidando su propio caso, nos sitúan en las coordenadas de una situación histórica e ideológica concreta en la que se enmarca su biografía, y que denota la interiorización de 
unos valores y criterios sobre "la mujer" profundamente enraizados en la sociedad de la que forma parte.

Vemos como en las obras comentadas hasta ahora, el problema principal es si las mujeres están capacitadas para la actividad creativa, y, también, los escritos de algunas autoras se convierten en una reivindicación sobre la existencia y legitimidad de mujeres artistas, tanto en España como en otros lugares del mundo occidental. Estas ideas y la justificación de las causas que motivan a las mujeres a crear obras artísticas, pervivirá en muchos escritos de autoras del siglo XX. Como podemos intuir, estas formas de justificar la realización de obras artísticas por las mujeres, constituye una reacción y una defensa ante el gran número de autores masculinos que cuestionan esta presencia y capacidad creativa de las mujeres artistas, y especialmente se aprecia que en todas las obras sobre artistas femeninas y en otros escritos se reivindica una mejor educación para las mujeres.

Así, en 1938, Ma Pilar Oñate, en una obra que reivindica la literatura "femenina" y la ampliación de profesiones y actividades laborales para las mujeres, aún encontramos las mismas ideas sobre la incapacidad de genio artístico en las mujeres:

La capacidad intelectual femenina, núcleo de la contienda feminista desde el Renacimiento, se acepta en la actualidad con la salvedad de la aptitud de la mujer para el trabajo creador y original propio del genio. La Biología actual niega a la mujer la capacidad genial, y la Historia no nos ofrece todavía ejemplos que oponer a esta teoría. Reconocida la aptitud de la mujer para las actividades no geniales que son casi todas, le queda abierto el acceso para las profesiones liberales, que hasta hace poco monopolizaba el hombre. Sin embargo, el cuidado del hogar y, sobre todo, la maternidad imponen en el ejercicio de las actividades femeninas limitaciones y diferencias que los más decididos feministas no pueden menos de reconocer. (Oñate 1938: 238)

De nuevo, las convenciones ideológicas establecidas, como en escritos anteriores, sobre la inexistencia del genio creador en la mujer, y la biología y la ciencia avalando estas ideas, a pesar de la reivindicación del ejercicio de nuevas actividades y profesiones para las mujeres. 
En los años 40 surgen también algunas monografías que reivindican el nombre y el trabajo de algunas artistas españolas. En Méjico, en el exilio tras la Guerra Civil, se publica la lujosa monografía publicada por la Editorial Losada sobre la figura y la obra de Maruja Mallo, que entre 1942 y 1945 gozó de un extraordinario prestigio y popularidad. Con textos de Ramón Gómez de la Serna, se recogían asimismo sus conferencias de 1937 Proceso histórico de la forma en las artes plásticas y Lo popular en la plástica a través de mi obra. Los escritos y artículos periodísticos de Maruja Mallo se encuentran intrínsecamente vinculados a su producción creadora en las artes plásticas y constituyen el entramado teórico e ideológico que nos desvela las claves de su pensamiento y de la actividad intelectual que la impulsaron a la realización de sus obras, en unos momentos históricos en los que una mujer no debía ser activa, creadora,

En España, a pesar de las consignas del régimen franquista sobre la mujer, que la relegaban a un papel menor y dependiente del hombre, dirigiéndola a las actividades domésticas y a las labores del hogar y la costura como en el siglo XIX, María Lafitte, Condesa de Campo Alange, publicó en 1944 una monografía sobre María Blanchard (1881-1932), una de las más importantes artistas españolas, que realizó su obra artística fundamentalmente en París, donde falleció en 1932. María Laffitte (1902-1986) no sólo publicó el libro María Blanchard, ahondando en la creación plástica de una pintora y haciéndola visible en España, sino que en 1948 publicó La secreta guerra de los sexos (Laffite 1948), obra pionera del feminismo intelectual y filosófico y anterior a El segundo sexo de Simone de Beauvoir. También publico numerosos libros y ensayos en las que trataba el tema de la mujer. Fundó, dirigió y patrocinó el Seminario de Estudios de la Mujer (SESM) que durante veinte años reunió a profesionales, profesoras universitarias e investigadoras, siendo el pionero de otros centros similares posteriores.

A partir de los años 60 se comienzan a publicar diversas obras que reivindican el papel de las mujeres en las artes. Así la obra de Carmen Pérez Neus, pintora ella misma, Galería Universal de Pintoras (Pérez-Neus 1964), que constituye un compendio a modo de catálogo de las pintoras conocidas en los diferentes países, y que, en el caso de España, toma sus datos en gran medida de la obra de Parada y Santín. En esta obra proporcionaba 
información sobre las biografías y obras de pintoras europeas y americanas, especialmente del siglo XIX, tratando de reivindicar la creación artística de las mujeres.

También esta reivindicación se encontraba tras el establecimiento del Salón Femenino de Arte Actual, en el que muchas artistas se unieron para dar a conocer su trabajo de creación. Se llevó a cabo en la Sala Municipal de Exposiciones y la Capilla del Hospital de la Santa Cruz de la ciudad de Barcelona desde 1962 a 1971, a raíz de la iniciativa de varias artistas (Gloria Morera, María Asunción Raventós, Mercedes de Prat y María Calvet en Madrid), con el objetivo de que el trabajo de creación plástica de las mujeres consiguiese un mayor apoyo institucional y una mayor repercusión social que evitase su "invisibilidad" en el mundo artístico. En el prólogo, $\mathbf{M}^{\mathrm{a}}$ Aurelia Capmany analiza los temas y las dificultades que en aquellos momentos (1969) encontraban las mujeres en la sociedad, y en los ámbitos específicos del arte, para hacer valer su presencia y el fruto de su trabajo de creación plástica, en el contexto de la sociedad española del momento. Los catálogos son el testimonio de la obra creativa de muchas artistas españolas de aquel momento que trataban de mostrar sus obras al público y encontrar el reconocimiento en el contexto del arte español.

En 1975, en el que se celebró el “Año Internacional de la Mujer”, y con ocasión del catálogo de la exposición celebrada con este motivo La mujer actual en la cultura, Isabel Cajide, crítica de arte y organizadora de la exposición, realizaba en el prólogo un balance sobre la situación de las mujeres en la cultura y en el arte en esos momentos. El texto es, por una parte, una amarga queja de la escasa entidad y valoración del trabajo artístico de las mujeres tanto en el pasado como en el momento en que escribe, y por otro, una justificación de la escasa presencia de las mujeres en el campo del arte, como en otros ámbitos académicos o artísticos, debido al papel que le fue asignado en la sociedad:

El talento necesita comprobar hallazgos, integrarse en el ambiente que le sirve de estímulo y levadura. No es justo afirmar que la mujer está incapacitada para toda función creadora. Mas bien sería sensato pensar que sin estas oportunidades, incapacitada para prosperar fuera de las funciones que se le habían asignado, haya conseguido, -iy a qué velocidad!- recobrarse de una paralización de siglos; que su talento, los dones naturales que Dios otorgó al género humano, no se abotargase y adquiriese irremediablemente hábitos impropios de su función "hombre" con su 
noble destino de ser portador de valores eternos. [...] Porque a finales del siglo XX, cuando se ha llegado a la luna, en los organismos internacionales se da el mismo valor a los papúes y a los ciudadanos franceses y se plantea en serio la todavía utopía del ocio, la mujer sigue encontrando dificultades, como lo demuestra la proclamación de este Año Internacional de la Mujer. (Cajide 1975: Prólogo)

En 1976 Raul Chavarri escribe Artistas Contemporáneas en España, que, como en casos anteriores, es una relación de artistas que tienen prestigio y notoriedad en aquellos momentos. En el prólogo, las palabras del autor, entre condescendientes y galantes, nos retrotraen a las posturas masculinas con las pintoras del siglo XIX.

No podemos olvidar las memorias de Amalia Avia (1930-2010), una destacadísima pintora contemporánea, que en su obra refleja tanto la situación general como los problemas y dificultades a que debían enfrentarse las mujeres que decidían ser artistas durante los años del franquismo. A través de sus páginas, podemos rememorar hechos de nuestro pasado reciente, a través de las vivencias personales de la autora que reflejan, de nuevo, la lucha de las mujeres por acceder a los ámbitos artísticos como creadoras:

En una inmensa clase de suelo de madera polvorienta, con los banquillos de dibujar puestos en círculo alrededor de la tarima de la modelo, nos sentábamos los alumnos. Los había de todos los géneros: estudiantes de la Escuela de San Fernando, pintores viejos, estudiantes de arquitectura, dibujantes..., pero aparte de nosotras, casi ninguna mujer. (Avia 2004: 200)

Un artículo de la periodista Enriqueta Antolín nos aporta información sobre lo que opinan algunas de las artistas más relevantes de la actualidad: "Somos poquísimas. En las muestras colectivas las mujeres no pasamos nunca de un 6\%. En Europa y en América se está haciendo un poco mejor, aunque todavía hay mucho que reivindicar. Hay muestras internacionales en las que entre un montón de varones aparece una sola mujer, y en España todavía peor" (Antolín 1998:34).

A pesar de los avances en la situación de las mujeres en estos dos siglos, y de las conquistas realizadas a partir del establecimiento de la democracia en España, el texto 
resume algunas de las cuestiones fundamentales del presente artículo: la lucha de las mujeres por hacer visible su trabajo de creación plástica y por que su voz sea escuchada en la sociedad, sus dificultades de todo tipo, incluidas las de la propia aceptación e interiorización de su papel secundario y menor, a partir de la ideología que se ha inculcado a las mujeres desde tiempos remotos y que sigue aún presente en la sociedad de nuestros días, el tratamiento de los temas establecidos, a través de una visión y una percepción de género diferente a la mostrada por artistas varones, $\mathrm{y}$, finalmente, a pesar de los profundos cambios acaecidos en la sociedad, como consecuencia de la propia dinámica de la evolución histórica, y que han permito a la mujer acceder a una mejor situación en la mayor parte de los ámbitos (educativo, económico, etc.), la permanencia de obstáculos y prejuicios, en la España de nuestros días, que aún impiden una total asimilación con respecto a los varones.

A partir de los años 70 del siglo XX las corrientes feministas en el arte comenzaron a cuestionar los presupuestos iconográficos presentes en la cultura de todas las épocas, tratando de ofrecer alternativas desde la identidad femenina. Muchas artistas tratan de presentar una nueva lectura del cuerpo femenino, incorporando lo biológico y la experiencia del cuerpo específica de las mujeres en ocasiones con desgarro y dolor, pero también con ironía, distanciamiento y humor. El objetivo de sus imágenes "intentaba ensalzar la diferencia sexual y afirmar la otredad de la mujer, sustituyendo las connotaciones de la inferioridad femenina por la de un orgullo respecto al cuerpo y la mente de la mujer" (Chadwick 1992: 322).

También se desarrollaron estrategias políticas de carácter reivindicativo, como las acciones de Guerrilla Girls en los años 80 en Estados Unidos. Se trataba de un grupo de artistas, escritoras y directoras de cine que con ocasión de la exposición en el Museum of Modern Art de Nueva York, titulada "An Internacional Survey of Painting and Sculpture", en la que de los 169 participantes tan sólo 13 eran mujeres, se manifestaron delante del museo contra esta desigualdad. A partir de esta experiencia, el grupo comenzó a poner en evidencia al mercado del arte, anunciando con carteles en las calles de la ciudad la forma en que se había utilizado el cuerpo femenino en la historia del arte, y la exclusión de las artistas del círculo del arte. Otras artistas denunciaron los estereotipos y 
convenciones sobre la mujer en la historia, como en el caso de Cindy Sherman, que realiza fotografías de sí misma con los diferentes disfraces que ha asumido la imagen de la mujer en la historia del arte, o Ana Mendieta, cuya obra se convierte en una metáfora de la experiencia femenina, en la que relaciona a la mujer con la tierra. Algunos de sus trabajos muestran la violencia contra el cuerpo de la mujer, perfilando en la tierra con materiales diversos, cuerpos que nos hablan de mujeres con pequeñas vidas, o de vidas maltratadas y torturadas, y que nos recuerdan a rituales ancestrales.

De entre las muchas artistas que desde los años 70 han producido una obra en la que han tratado de denunciar la violencia implícita o explícita en la vida de las mujeres, sus miedos y sus sentimientos de culpa, destacamos tan sólo a tres: Louise Bourgeois (1911), Nancy Spero (1926) o la española Eulalia Valldosera (1963) entre otras. También mujeres procedentes de otros contextos culturales nos muestran a través de su trabajo su reflexión artística sobre la mujer, el colonialismo y sus implicaciones de género, o la discriminación por raza, género o clase social.

El surgimiento del movimiento feminista ha tenido un enorme impacto no sólo en el arte de las mujeres sino también en un gran número de publicaciones que, en el campo artístico, reivindicaban el trabajo creativo de muchas mujeres a lo largo de la historia, que ha sido ignorado y ninguneado en las publicaciones académicas hasta el presente. De entre las publicaciones surgidas fundamentalmente en el ámbito anglosajón, destacamos algunos libros y artículos: Women Artists (Bachmann y Piland 1982), "Women's Performance Art: Feminism and Postmodernism" (Forte 1988), Women Artists, 15501950 (Harris y Nochlin 1978), Women Artists and the Pre-Raaphaelite Movement (Mars y Nunn 1989), Old Mistresses. Women, Art and Ideology (Parker y Pollock 1981), Imagining Women (Bonner 1992), Feminism and Art History. Questioning the Litany (Broude y Garrard 1982) o The Aesthetics of Power. Essays in Critical Art History, (Duncan 1993) entre otras valiosas obras que se han publicado en los últimos años.

De entre las traducidas y editadas en español, Mujer, arte y sociedad (Chadwick 1992), Nueva crítica feminista de arte (Deepwell 1998), Estética feminista (Ecker 1986), Mujeres Artistas. National Museum of Women in the Arts (Fisher Sterling 1995), La 
carrera de obstáculos (Greer 2005 [1979]), Mujeres artistas de los siglos XX y XXI, Colonia (Grosenick 2005), El desnudo femenino (Nead 1998) o las obras de estética Feminista como Nueva crítica feminista de arte (Deepwell 1998) o Estética feminista (Ecker 1986) entre otras.

En España también se han publicado muchas obras en las que se investigan y analizan las producciones y la situación social de las artistas españolas. De entre ellas destacamos La mujer y la pintura del XIX español. (Cuatrocientas olvidadas y algunas más) (1987) de Estrella de Diego, en el que, como el título indica, se sacan a la luz los nombres y las obras de muchas artistas del siglo XIX, y en el que también se desvelan las condiciones de su trabajo creativo, los temas, formatos y tamaños de muchas artistas olvidadas, y otros aspectos del trabajo creativo de las mujeres en el siglo XIX. Se trata de un valioso trabajo pionero en la investigación histórica sobre artistas españolas, que ofrece importantes sugerencias para la investigación en la metodología y las cuestiones y temas tratados.

También con el objetivo de mostrar los nombres y las obras que crearon muchas artistas del XIX, el libro de I. Coll, Diccionario de mujeres pintoras en la España del siglo XIX (2001), en el que se hace una relación de biografías de artistas y obras, olvidadas por la historiografía del arte. Dentro de una reivindicación general de la creación artística de las mujeres y de divulgación, las obras de $\mathrm{M}^{\mathrm{a}}$ Teresa Alario Trigueros Arte y feminismo (2008), la de Marián F. Cao (coord.) Creación artística y mujeres. Recuperar la memoria, (Madrid, 2000), la de Bea Porqueres Reconstruir una tradición (Las artistas en el mundo occidental) (1994), o la de Amparo Serrano de Haro Mujeres en el arte. Espejo y realidad, (2000). Con abundante información biográfica y visual, la obra de Victoria Combalia Amazonas con pincel. Vida y obra de las grandes artistas del siglo XVI al siglo XXI (2006). Igualmente encontramos la obra de Patricia Mayayo Historias de mujeres, historias del arte (2007), un ensayo en la línea de los trabajos de las escritoras e investigadoras norteamericanas e inglesas, en el que reflexiona sobre cuestiones como la indagación de las mujeres artistas en la historia, las diferencias iconológicas entre hombres y mujeres, los modelos femeninos en el imaginario artístico, cómo mirar un cuadro con una mirada crítica desde la perspectiva de mujer, o la mujer y las nuevas 
tecnologías. Y en una línea de indagación sobre las artistas españolas más actuales, la obra de Juan Vicente Aliaga y Patricia Mayayo (ed.) Genealogías feministas en el arte español: 1960-2010 (2013), que nos ofrece abundante información sobre exposiciones y artistas españolas de las últimas décadas, así como de las bibliografías que se han ocupado en los últimos tiempos del arte de las mujeres. Es una obra de máxima actualidad que nos permiten conocer los últimos desarrollos del tema.

Y con el objetivo de reivindicar y divulgar las obras de mujeres existentes en los museos, la obra de Vicente Ibiza i Osca, Obra de mujeres artistas en los museos españoles (2006), que, como su nombre indica, expone una relación de obras y de autoras en museos españoles, pero que previamente lleva a cabo una muy interesante aportación histórica sobre la presencia de mujeres artistas en la historia del arte y la situación de las diferentes artistas en sus contextos de referencia. También la obra de Marián López Fernández Cao, Antonia Fernández Valencia y Asunción Bernárdez Rodal (eds.) El protagonismo de las mujeres en los museos (2012).

Se han publicado también un gran número de monografías sobre artistas españolas, como, entre otros muchos, los dedicados a las cuatro artistas más importantes del primer tercio del siglo XX, María Blanchard, como el de la exposición dedicada a la artista en el Museo Nacional Centro de Arte Reina Sofía (2012), y otros de importantes exposiciones dedicadas a esta artista, el dedicado a Maruja Mallo (2009), a Remedios Varo , con la importante monografía editada en Méjico, tras la salida hacia en exilio. En Méjico alcanzó un gran éxito desde su primera exposición en 1954, y allí es considerada una pintora mejicana (1998). La última gran artista es Ángeles Santos, sobre la cual existe una importante publicación de Vinyet Panyella (1992).

Del mismo modo, se han publicado diversos catálogos de exposiciones que tratan el tema de las mujeres artistas, desde un punto de vista general, como el de la exposición Amazonas del Arte Nuevo (29 enero/30 marzo de 2008, Madrid 2008), a específicos sobre artistas españolas, como la celebrada en el Centro Cultural del Conde Duque del Ayuntamiento de Madrid, que dirigía Enrique Tierno Galván, Mujeres en el Arte Español (1900-1984) (Madrid, 1984), o el de Fuera de Orden. Mujeres de la Vanguardia 
Española (10 febrero/18 abril 1999) (Madrid, 1999). Éstas son tan sólo una muestra del gran número de publicaciones que han tratado el tema de las mujeres en el Arte, tanto en el contexto internacional, como en el de nuestro país, en el que, aunque de forma no tan numerosa, también se han publicado un gran número de artículos y otras obras que no he considerado en esta comunicación.

Quiero ahora comentar las aportaciones que yo misma he hecho al tema. En 2003 publiqué Mujeres españolas en las Artes Plásticas, una obra de divulgación sobre la obra de creación plástica de muchas artistas españolas desde la Edad Media hasta 1990, y que ha tenido muy buena acogida en los medios académicos. Mi última publicación es Artistas españolas en la dictadura de Franco. 1939-1975, una obra de investigación en la que analizo la situación de las mujeres en los distintos periodos cronológicos de la dictadura, e indago sobre la situación y expectativas de las artistas. No se trata, sin embargo, de una relación pormenorizada de las artistas del periodo, sino de una investigación histórica. Con esta modesta aportación me sumo a las autoras e investigadoras que han tratado de dar visibilidad y reivindicar las creaciones artísticas de las mujeres de todas las épocas históricas. Pero, ¿cuál es la línea argumental e ideológica que han seguido todas estas publicaciones hasta el momento presente?

En los primeros escritos las autoras se rebelaban contra la ideología hegemónica que negaba la existencia de mujeres artistas y la capacidad creadora de las mujeres. Esto se inscribía en un malestar provocado por las ideas de autores varones que, dentro de una atávica tradición, situaba a la naturaleza femenina fuera de los campos de la creación artística e intelectual. Algunas autoras desde finales del siglo XIX y en el primer tercio del siglo XX reivindicaron especialmente mejoras educativas para las mujeres y manifestaron cómo la posición de las mujeres en la estructura social había impedido un mayor desarrollo en los campos del arte y la cultura.

Sin embargo, se advierte en algunas de sus obras la influencia de las ideas ambiente que consideraba la imposibilidad de genio artístico en la mujer. Y desde comienzos del siglo XX comienzan a aparecer en España libros que realizan una relación de mujeres artistas en los siglos pasados, como el de José Parada y Santín en 1903, impulsados, 
seguramente, por el deseo de reivindicar su actividad dentro de una tradición y una genealogía de mujeres artistas, por parte de las pintoras que asistían a las academias de arte, como la del mismo Parada y Santín.

A partir del movimiento feminista surgido fundamentalmente en el ámbito anglosajón, especialmente desde los años 60 del siglo $\mathrm{XX}$, diversas autoras e investigadoras han rescatado del olvido los nombres y las obras de mujeres artistas desde la Edad Media, contextualizándolas en las diversas épocas históricas y poniendo en evidencia el discurso patriarcal que subyacía y subyace en la mayoría de autores de las bibliografías especializadas y consagradas de la historia del arte. Esto ha permitido que se incrementase notablemente el número de artistas y el reconocimiento de su presencia en la actividad artística a lo largo del tiempo, así como de un mayor conocimiento de las condiciones en las que tuvieron que desarrollar su vida y su trabajo.

Pero esta búsqueda de la integración de las mujeres en los parámetros establecidos de la historiografía artística no parecía suficiente a autoras como Rozsika Parker y Griselda Pollock, en el panorama internacional, o como Patricia Mayayo, en el ámbito nacional, que han contribuido a poner en entredicho la jerarquía de valores del canon establecido por la literatura artística de todos los tiempos, incluida la época actual, y que requiere, por parte de las/los investigadores, un exhaustivo análisis que permita desentrañar los discursos y prácticas de la historia del arte y en lo que muchas de las obras citadas inciden de forma penetrante.

\section{Referencias bibliográficas}

Alario Trigueros, $\mathrm{M}^{\mathrm{a}}$ Teresa. 2008. Arte y feminismo. Donostia-San Sebastián: Nerea.

Aliaga, Juan Vicente y Patricia Mayayo (ed.). 2013. Genealogías feministas en el arte español: 1960-2010. Madrid: This Side Up.

Antolín, Enriqueta. 1998. "Qué pintan las mujeres. Poca presencia internacional y precios más bajos, parte del tratamiento discriminatorio hacia las artistas", Diario "El País", 6 de diciembre: 34 . 
Avia, Amalia. 2004. De puertas adentro. Memorias. Madrid: Taurus.

Bachmann, Donna \& Sherry Piland. 1982. Women Artists. New York: Scarecrow Press.

Bonner, Frances (ed.). [1992] 2000. Imagining Women. Cambridge: Polity Press.

Broude, Norma \& Mary Garrard (ed.). 1982. Feminism and Art History. Questioning the Litany. New York: Harper \& Row.

Burgos, Carmen de. 1927. La mujer moderna y sus derechos. Valencia: El Adelantado de Segovia.

Cajide, Isabel. 1975. La mujer en la cultura actual. Catálogo del Año Internacional de la Mujer, Palacio de Fuensalida (Toledo) Madrid: Dirección General del Patrimonio Artístico y Cultural, Ministerio de Educación y Ciencia, Madrid. Octubre.

Cao, Marián L.F. (coord.). 2000. Creación artística y mujeres. Recuperar la memoria. Madrid: Nancea.

Catálogo Eulalia Valldosera. Dependencias. 2009. Madrid: Museo Nacional Centro de Arte Reina Sofía, mayo.

Catálogo en el Año Internacional de la Mujer 1975. La mujer en la cultura actual. Madrid: (Palacio de Fuensalida, Toledo. Octubre de 1975. Dirección General del Patrimonio Artístico y Cultural, M. E.C., Prólogo.

Catálogo VIII Salón Femenino de Arte Actual. 1969. Barcelona.

Catálogo Mujeres en el Arte Español (1900-1984). 1984. Madrid: Centro Cultural del Conde Duque; Ayuntamiento de Madrid.

Catálogo razonado. 1998. Remedios Varo. Méjico: Ediciones Era.

Catálogo Fuera de Orden. Mujeres de la Vanguardia Española (10 febrero/18 abril 1999). 1999. Madrid: Fundación Cultural MAPFRE VIDA.

Catálogo Amazonas del Arte Nuevo. 29 enero/30 marzo de 2008. Madrid: Fundación MAPFRE.

Catálogo Maruja Mallo. Exposición 10 septiembre 2009-10 enero 2010. 2009. Madrid: Casa das Artes, Vigo- 26 enero-4 abril 2010, real Academia de San Fernando.

Catálogo María Blanchard, cubista. Exposición retrospectiva. Madrid: Fundación Botín: 22 junio-16 septiembre-Museo Nacional Centro de arte Reina Sofía: 16 0ctubre 2012-25 febrero 2013.

Ceán Bermúdez, Juan Agustín. 1800. Diccionario de los más ilustres profesores de las Bellas Artes en España. Madrid: Viuda de Ibarra.

Coll, Isabel. 2001. Diccionario de mujeres pintoras en la España del siglo XIX. Barcelona: Centauro Groc. 
Combalia, Victoria. 2006. Amazonas con pincel. Vida y obra de las grandes artistas del siglo XVI al siglo XXI. Barcelona: Ediciones Destino.

Chadwick, Witney. 1992. Mujer, arte y sociedad. Barcelona: Destino.

Chavarri, Raúl. 1976. Artistas españolas contemporáneas. Madrid: Gavar.

De Diego, Estrella. 1987. La mujer la pintura del XIX español. Madrid: Ensayos Arte Cátedra.

Deepwell, Katy (ed.). 1998. Nueva crítica feminista de arte. Madrid: Cátedra.

Duncan, Carol. 1993. The Aesthetics of power (Essays in critical Art History). Cambridge: Cambridge University Press.

Ecker, Gisela (ed.). 1986. Estética feminista. Barcelona: Icaria.

Eulate Sanjurjo, Carmela. 1917. La mujer en el arte. Sevilla: Imp. de F. Díaz y C. ${ }^{a}$ Forte.

Jeanie, Forte.1988. "Women's Performance Art: Feminism and Postmodernism", Theatre Journal, vol. 40, 2: 217-235.

Fisher Sterling, Susan. 1995. Mujeres Artistas. National Museum of Women in the Arts. New York-Madrid: Abbeville-Cátedra.

Gimeno de Flaquer, Concepción. 1877. La mujer española. Estudios acerca de su educación y sus facultades intelectuales. Madrid: Imprenta y Librería de Miguel Gemarro.

. 1915. Mujeres de regia estirpe Madrid: Administración de El Album Iberoamericano.

Greer, Germaine. 2005 [1979]. La carrera de obstáculos. Madrid: Bercimuel.

Grosenick, Uta (ed.). 2005. Mujeres artistas de los siglos XX y XXI. Colonia: Taschen.

Harris, Ann Sutherland \& Linda Nochlin. 1978. Women Artists, 1550-1950. Los Angeles County Museum.

Ibiza I Osca, Vicent. 2006. Obra de mujeres artistas en los museos españoles. Valencia: Centro Francisco Tomás y Valiente, UNED Alizira-Valencia, Colección Interciencias.

Laffite, María. 1944. María Blanchard. Madrid: Hauser y Menet. 1948. La guerra secreta de los sexos. Madrid: Revista de Occidente.

López Fernández, María. 2006. La imagen de la mujer en la pintura española (18901914). Madrid: La Balsa de la Medusa. 
López Fernández Cao, Mariám et al. (eds.). 2012. El protagonismo de las mujeres en los museos. Madrid: Edit. Fundamentos.

Marsh, Jan \& Pamela Gerrish Nunn. 1989. Women Artists and the Pre-Raaphaelite Movement. London: Virago Press Limited.

Mayayo, Patricia. 2007. Historias de mujeres, historias del arte. Madrid: Ensayos Arte Cátedra.

Muñoz López, Pilar. 2003. Mujeres españolas en las Artes Plásticas. Madrid: Ed. Síntesis.

2014. Artistas españolas en la dictadura de Franco. 1939-1975. Sevilla: Editorial Arcibel.

Nead, Linda. 1998. El desnudo femenino, Madrid: Tecnos.

Nuñez Rey, Concepción. 2005. Carmen de Burgos "Colombine” en la Edad de Plata de la literatura española. Sevilla: Fundación José Manuel Lara.

Oñate, $M^{a}$ del Pilar de. 1938. El feminismo en la literatura española. Madrid: EspasaCalpe.

Panyella, Vinyet. 1992. Ángeles Santos. Barcelona: Viladot.

Parada y Santín, José. 1903. Las pintoras españolas. Madrid: Imprenta del Asilo de Huérfanos del Sagrado Corazón de Jesús.

Pardo Bazán, Emilia. 1890 [1976]. La mujer española y otros artículos feministas. Madrid: Ed. Nacional.

Parker, Rozsika \& Griselda Pollock. 1981. Old Mistresses. Women, Art and Ideology. London: Harper Collins.

Pérez Carreño, Francisca. 1993. Artemisia Gentileschi. Madrid: Historia 16.

Pérez-Neus, Carmen. 1964. Galería Universal de Pintoras. Madrid. Editora Nacional.

Pittaluga, Gustavo. 1946. Grandeza y servidumbre de la mujer. Buenos Aires: Editorial Sudamericana.

Porqueres, Beatriz. 1994. Reconstruir una tradición (Las artistas en el mundo occidental). Madrid: Horas y horas (Cuadernos inacabados, $\mathrm{n}^{\circ} 13$ ).

Serrano de Haro, Amparo. 2000. Mujeres en el arte. Espejo y realidad. Barcelona: Plaza \& Janés.

V.V.A.A. 1984. Mujeres en el arte español (1900-1984). Madrid: Centro Cultural del Conde Duque, Concejalía de Cultura, Ayuntamiento de Madrid. 
V.V.A.A. 1990. La imagen de la mujer en el arte español. Madrid: Actas de las Terceras Jornadas de Investigación Interdisciplinar, organizadas por el Seminario de Estudios de la Mujer de la Universidad Autónoma de Madrid, Ediciones de la Universidad Autónoma de Madrid.

Zambrano, María. 1947. “A propósito de la grandeza y servidumbre de la mujer”. Sur, vol.150: 58-69. 